\title{
Outlet Flow Velocity in Circular Culvert
}

\author{
Wojciech Szpakowski \\ Gdańsk University of Technology, Faculty of Civil and Environmental Engineering, \\ ul. G. Narutowicza 11/12, 80-233 Gdańsk, Poland, e-mail: wojciech.szpakowski@wilis.pg.gda.pl
}

(Received October 10, 2014; revised December 16, 2014)

\begin{abstract}
The outlet flow velocity in the end section of the culvert barrel depends in most cases on the culvert geometry, including the barrel slope, as well as on upstream and downstream channel parameters. Flowing water can create pressure flow or free surface flow in the culvert barrel. In the case of an unsubmerged barrel outlet, the free-surface flow is more frequent than the full flow. Increased velocities can cause channel bed scour and bank erosion downstream of the culvert outlet. Different culvert flow cases in which the barrel outlet is unsubmerged are presented in this paper. The influence of the flow regime on the outlet velocity is also discussed.
\end{abstract}

Key words: culvert conveyance, outlet velocity, circular culvert, critical flow

\section{List of Symbols}

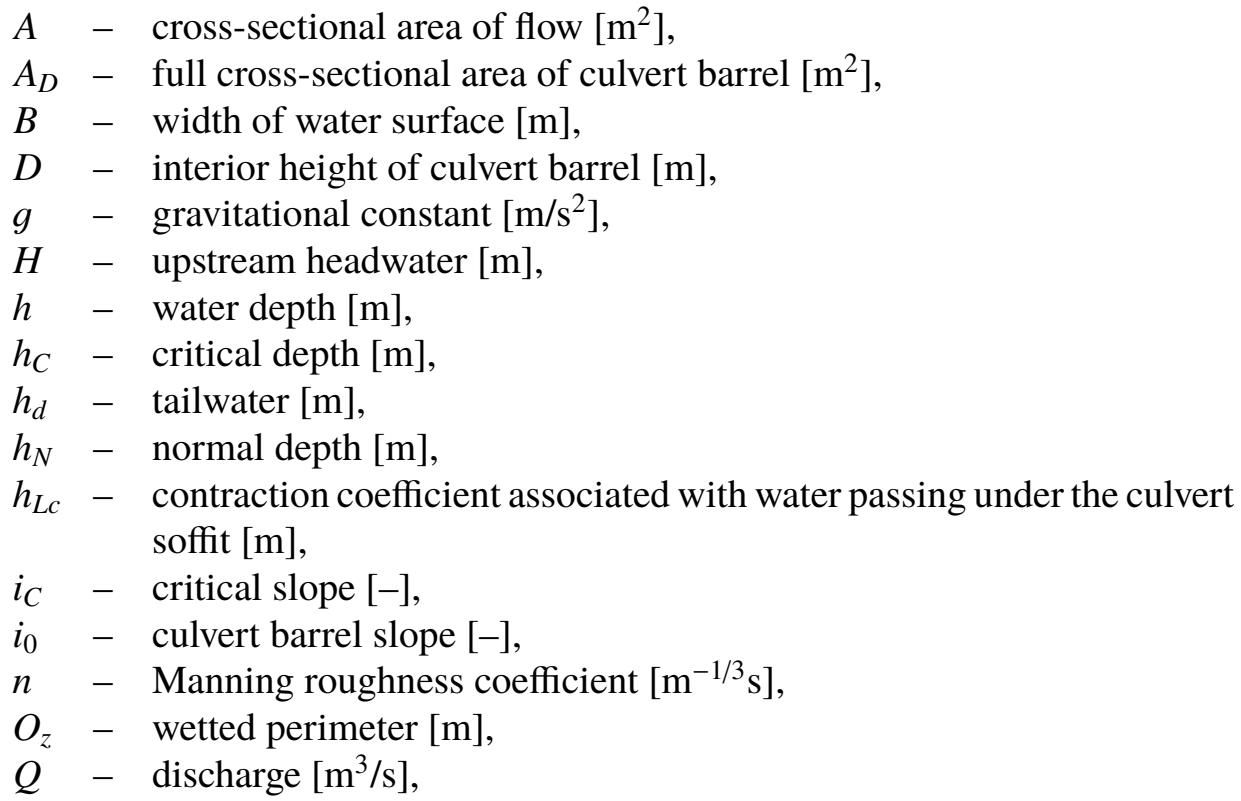




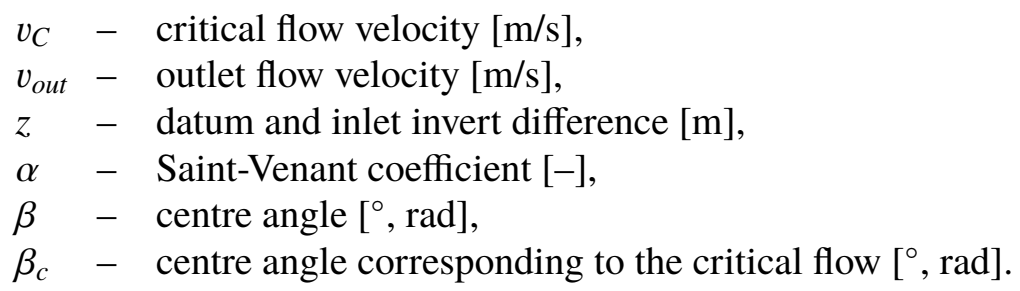

\section{Introduction}

Culverts are parts of a system which should safely convey storm water runoff through a roadway or railway system. Culverts can also have non-hydraulic functions, such as providing a passage for small animals. Commonly used cross-sectional shapes are closed conduit and open bottom culverts. The most common closed conduit shapes are box, or rectangular, and circular. Elliptical and pipe arch shapes are more popular in small bridge structures. Open-bottom culverts are used to provide passage for aquatic animals. This type of culverts makes it possible to reduce the water velocity compared with closed conduits. A culvert structure consists of an inlet construction, a barrel, an outlet construction and a bed and bank protection system below the barrel (Fig. 1).

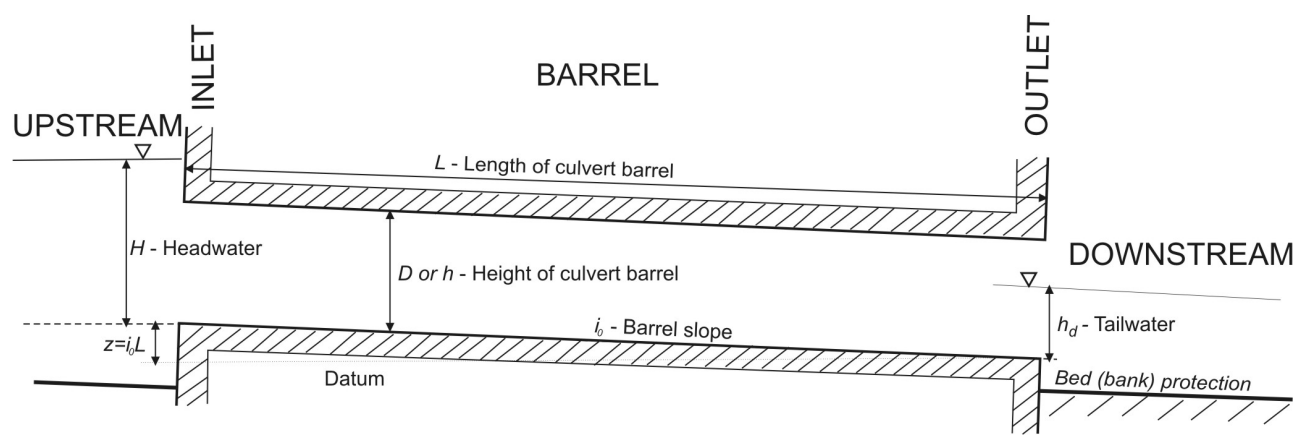

Fig. 1. Scheme of the culvert structure

Culvert inlets are prefabricated or constructed on the installation site. Currently, technical solutions for the most common culvert inlets include a projecting barrel and a barrel entrance mitered to slope. To increase culvert conveyance, headwalls or wingwalls are also often used in this type of structure.

A variety of materials are used in the construction of culverts. The most common are reinforced or non-reinforced concrete, different types of plastic pipes (high-density polyethylene or polyvinyl chloride) and corrugated metal forms.

\section{Culvert Hydraulics}

A real flow in a culvert system results from non-steady runoff. A culvert design based on the steady flow condition should allow the peak flow to pass through the structure in 
a safe way. Sudden changes in the velocity-depth relationship, and rapidly varied flow can often be observed in the culvert vicinity and inside the barrel. In most cases, the water flow upstream of the culvert is subcritical. Water contraction in the vicinity of the culvert entrance causes local energy loss. Inside a partly filled culvert, water flow can be subcritical, critical or supercritical. Water can also fill the barrel volume partially or entirely. Whenever flow changes from supercritical to subcritical, hydraulic jumps will form either inside the barrel or downstream of the culvert structure.

With a great number of possible flow regimes, the United States Geological Survey (USGS) distinguishes six types which occur in most cases (Bodhaine 1968, French 2007) (Fig. 2). Types 1-3 apply to an unsubmerged culvert inlet, unlike flow types 4-6. Free-surface flow in the culvert barrel is assumed in flow types 1-3 and 5. Pressure flow in the culvert barrel is assumed in types 4 (submerged outlet) and 6 (unsubmerged outlet).

In the calculation of culvert hydraulics, the commonly known continuity equation and the energy equation for flow between two control sections are applied. The upper control section (UCS) is located upstream of the culvert inlet in the channel section. The lower control section (LCS), in the case of free-surface barrel flow, is situated in the critical flow section. Depending on flow conditions, critical flow can occur along the whole length of the culvert barrel or not at all. When subcritical flow transforms into supercritical flow in the vicinity of the inlet, the lower control section is called the inlet control. In other cases, flow in the culvert barrel is subcritical and is controlled at the end of the culvert. Therefore, the lower control section is called the outlet control. Pressure flow inside the culvert is also controlled at the outlet.

Culvert conveyance influences water flow in the culvert barrel. Assuming the uniform flow and a limited tailwater impact on a specific head, a greater culvert slope causes a higher water speed inside the barrel. The outlet flow velocity in a free-surface flow seems to have a significant impact on downstream erosion when critical flow occurs inside the barrel. In three types of flow (1,2 and 5), the above conditions may occur (Fig. 2).

In type 1 flow, the slope of the culvert is higher than the critical slope, and both the inlet and the outlet are unsubmerged. Supercritical flow occurs inside the barrel, and the critical section is situated at the culvert inlet. In this case, the culvert barrel is capable of conveying more flow than the inlet can provide, so the culvert capacity depends only on the inlet configuration, the area of control section flow and the upstream water surface elevation. It should be mentioned that in the case of a significant headwater, pressure flow might occur in the culvert barrel (type 6 flow).

In type 2 flow, the culvert slope is lower than the critical slope, and both the inlet and the outlet are unsubmerged. In contrast to type 1, subcritical flow occurs in the barrel, and the critical section is situated at the outlet. The culvert capacity also depends on the roughness of the material used to fabricate the barrel, described by the Manning roughness coefficient. When downstream flow has an impact on water 
Type 1 - Unsubmerged inlet and outlet, critical depth at inlet

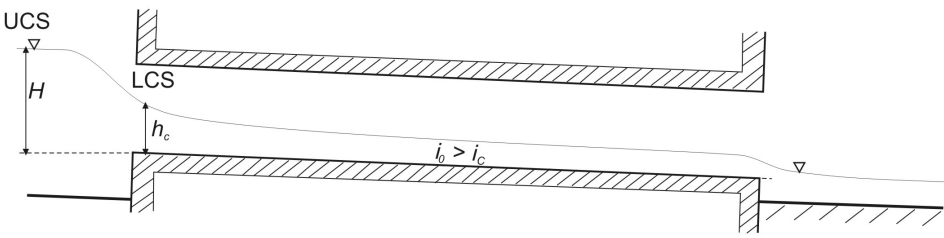

Type 2 - Unsubmerged inlet and outlet, critical depth at outlet

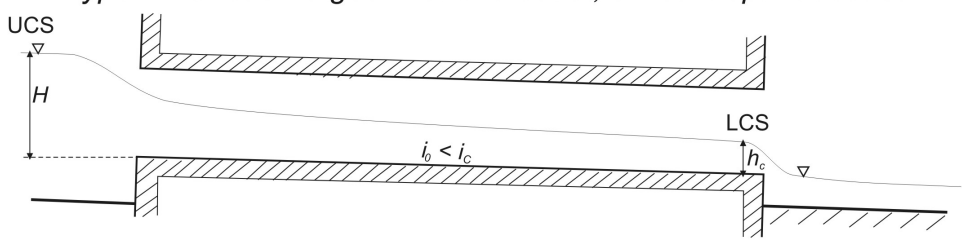

Type 3 - Unsubmerged inlet and outlet, subcritical flow throughout
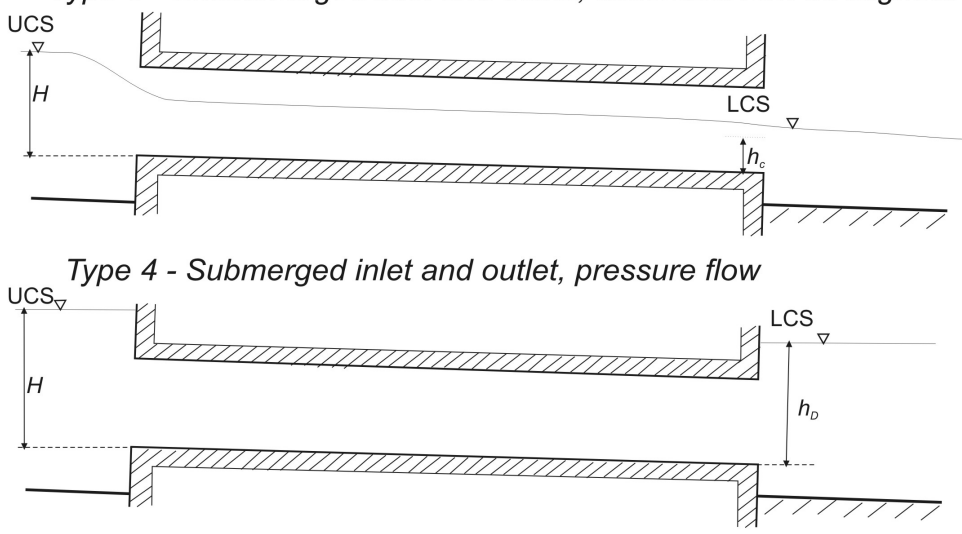

Type 5 - Submerged inlet and unsubmerged outlet,

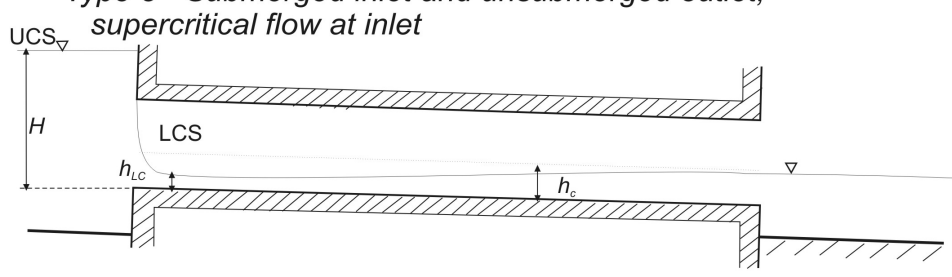

Type 6 - Submerged inlet and unsubmerged outlet,

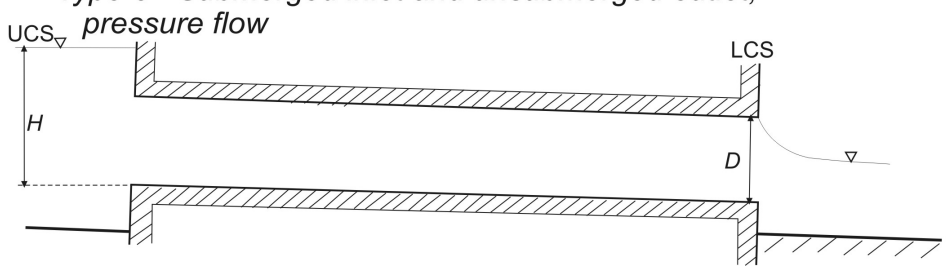

Fig. 2. Six basic types of culvert flow, UCS - Upper control section, LCS - Lower control section. (Based on Bodhaine (1968)) 
surface at the culvert outlet (above the critical depth, below the barrel height), critical flow does not occur in the barrel section, which leads to type 3 flow.

In type 5, the inlet is submerged, and the outlet is unsubmerged. The critical depth occurs downstream of the culvert entrance, and supercritical flow occurs in the upper section of the culvert barrel. In the lower control section, which is situated at the barrel inlet, the water depth $\left(h_{L c}\right)$ is lower than the critical depth. The depth of water in that section results from contraction associated with flow passing under the culvert soffit. When the barrel slope is lower than the critical slope, depending on the barrel length, a hydraulic jump may develop inside the culvert.

It should be mentioned that when the barrel slope is higher than the critical slope in flow types 1 and 5, submergence of the barrel outlet does not assure the lower control section location at the outlet (Fig. 3). In these two cases, the culvert barrel is partly filled with water, but free-surface flow with a critical section occurs in the vicinity of the barrel inlet. Flow in the barrel is supercritical until the place where a hydraulic jump occurs (Henderson 1966). Referring to Bodhaine (1968), the above two unusual sub-types of flow are added in the U.S. Department of Transportation Federal Highway Administration report (Schall et al 2012). Additionally, when the inlet and the outlet are both submerged, sub-atmospheric pressure could develop in the first section of the barrel, which might create an unstable condition and, in consequence, pressure flow described in type 4 flow.

Type $1^{*}$ - Unsubmerged inlet and submerged outlet, critical depth at inlet, hydraulic jump inside the barrel

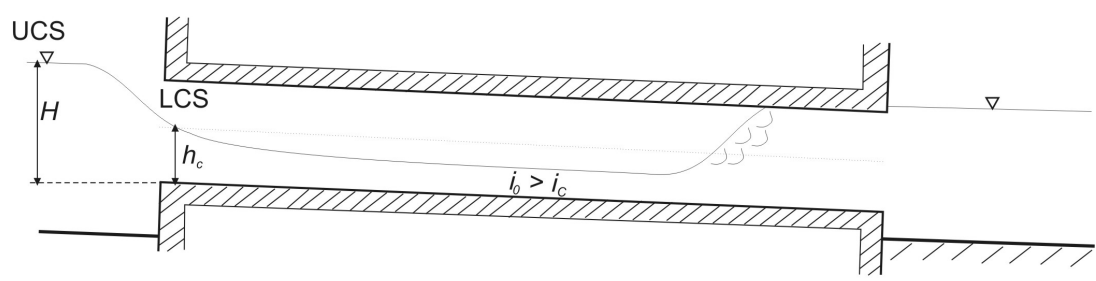

Type $5^{\star}$ - Submerged inlet and outlet,

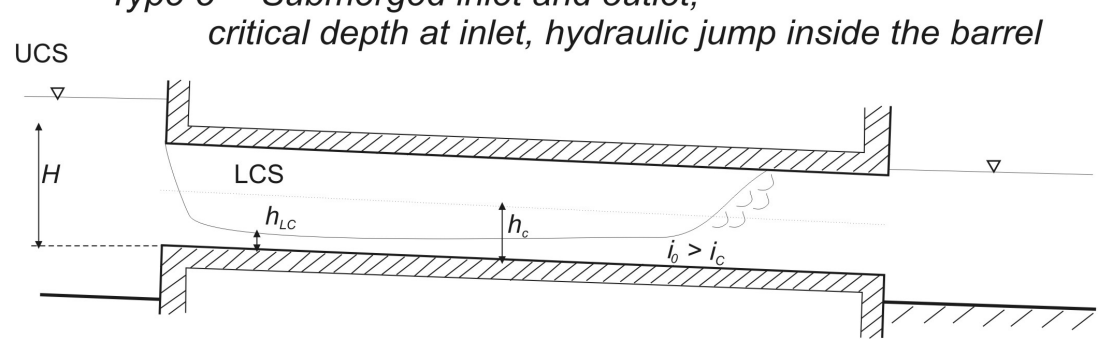

Fig. 3. Additional sub-types of culvert flow, UCS - Upper control section, LCS - Lower control section. (Based on FHWA (Schall et al 2012)) 


\section{Hydraulic Parameters of a Circular Culvert Barrel}

Comparing the cross-sectional areas at rectangular and circular culverts, the water surface width is variable with the water depth and the dimensions of a circular cross-section. A definition sketch for the geometry of a circular cross-section is presented in Figure 4.

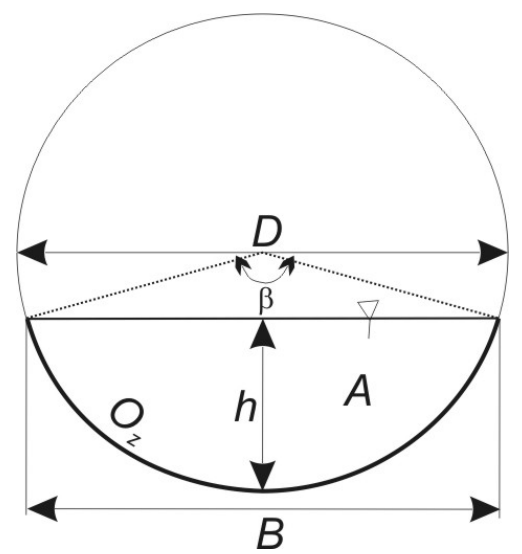

Fig. 4. Definition sketch for the geometry of a circular cross-section

The centre angle $-\beta$ is related to the water depth by the relation

$$
h=\frac{D}{2}\left(1-\cos \frac{\beta}{2}\right),
$$

The width of water surface $-B$, the cross-sectional area of flow $-A$ and the wetted perimeter of water $-O_{z}$ are defined as follows:

$$
\begin{gathered}
B=D \cdot \sin \frac{\beta}{2}, \\
A=\frac{D^{2}}{8}(\beta-\sin \beta), \\
O_{z}=\frac{D}{2} \cdot \beta .
\end{gathered}
$$

The first step to recognize the type of culvert flow is to determine the critical depth. The basic critical flow equation is defined as follows (Henderson 1966):

$$
\frac{A^{3}}{B}=\alpha \cdot \frac{Q^{2}}{g} .
$$

For a circular cross-section, the top width of water surface and the cross-sectional area of flow are functions of the centre angle corresponding to the critical flow - 
$\beta_{c}$. These two critical cross-sectional hydraulic parameters are defined similarly to equations 2 and 3 . The critical flow equation for a circular cross-section is defined as a nonlinear equation:

$$
\frac{D^{5}}{512} \cdot\left(\beta_{c}-\sin \beta_{c}\right)^{3}=\frac{\alpha \cdot Q^{2}}{g} \cdot \sin \frac{\beta_{c}}{2} .
$$

After rearranging the above equation in the form $f\left(\beta_{c}\right)=0$, the following formula is obtained:

$$
f\left(\beta_{c}\right)=\frac{D^{5}}{512} \cdot\left(\beta_{c}-\sin \beta_{c}\right)^{3}-\frac{\alpha \cdot Q^{2}}{g} \cdot \sin \frac{\beta_{c}}{2}=0 .
$$

$f\left(\beta_{c}\right)$ is a real continuous function in the domain $\left(0 \leq \beta_{c} \leq 2 \pi\right)$ and has two roots, one of which is equal to zero. The second root is the required solution (Fig. 5). For the central angle $\beta_{c}=2 \pi, f\left(\beta_{c}\right)$ is equal to $D^{5} / 512 \cdot(2 \pi)^{3}$. For example, for a pipe of diameter $D=1.2 \mathrm{~m}$, as shown in Fig. 5, the expression $D^{5} / 512 \cdot(2 \pi)^{3}$ is equal 1.206. Knowing that only one root is in the domain of the function $f\left(\beta_{c}\right)$, the bisection method (Szymkiewicz 2010) was used to calculate the central angle in the critical flow equation (7). The bisection method converges rather slowly, but it always leads to the solution and guarantees the result with an acceptable approximation of the root.

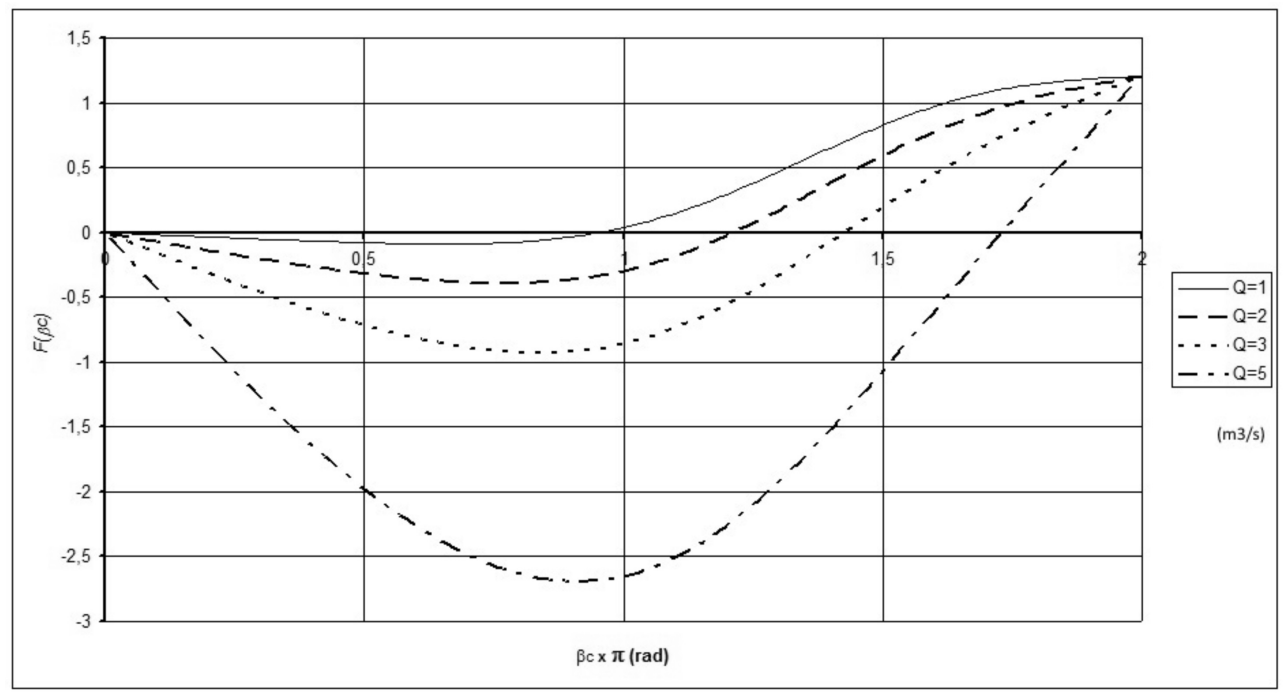

Fig. 5. Graph of the function $f\left(\beta_{c}\right)$ for a barrel height of 1.2 meter and variable discharge

\section{Outlet Flow Velocity Calculation}

A headwall circular culvert of diameter $1.2 \mathrm{~m}$ was assumed as an example for outlet flow velocity calculation. The barrel slope varies from 0.5 to 3.5 percent. The concrete culvert material is characterized by the Manning roughness coefficient $n=0.013$ 
$\mathrm{m}^{-1 / 3} \mathrm{~s}$, which corresponds to a new concrete surface. The culvert outlet is unsubmerged without any impact of downstream. For the unsubmerged inlet, the first type of culvert flow was used. When the headwater caused the submergence of the culvert entrance, type 5 flow was used.

The FHWA formulas were used in flow discharge calculations (Schall et al 2012). For the inlet control equation valid in the unsubmerged inlet flow (type 1 flow), based on the specific head at the critical depth, the FHWA formula has the following form:

$$
\frac{H}{D}=\frac{\left(h_{C}+\frac{v_{C}^{2}}{2 g}\right)}{D}+0.0078\left[\frac{1.811 \cdot Q}{A_{D} \cdot D^{0.5}}\right]^{2.0}-0.5 \cdot i_{0} .
$$

In the second term on the right-hand side of equation(8), the correction factors 0.0078 and 2.0 were determined on the basis of a real experiment conducted by the National Bureau of Standards (NBS) and commissioned by the U.S. Bureau of Public Roads. The number 1.811 results from metric to SI system unit conversion. There is also an element in equation (8) which designates the slope of the culvert barrel. However, this parameter has little effect on the final result. Equation (8) applies up to about $Q / A_{D} D^{0.5}=1.93$, which corresponds to a headwater-pipe diameter ratio of about 1.1.

For the submerged culvert entrance (type 5 flow), the FHWA formula including two correction factors (0.0379 and 0.69) and a metric-SI unit conversion parameter, is written as follows:

$$
\frac{H}{D}=0.0379\left[\frac{1.811 \cdot Q}{A_{D} \cdot D^{0.5}}\right]^{2}+0.69-0.5 \cdot i_{0} .
$$

Equation (9) applies above about $Q / A_{D} D^{0.5}=2.21$, which corresponds to a headwater-pipe diameter ratio of about 1.3. A direct relationship between headwater and culvert discharge was obtained for the submerged inlet condition (Eq. 9). For the unsubmerged condition, the culvert discharge value was initially assumed. The critical depth was estimated, and the headwater depth above the inlet control section invert was calculated by equation (8).

The outlet flow velocity was calculated as the mean velocity of flow at the outlet by the basic continuity equation using culvert discharge and the cross-sectional area of flow:

$$
v_{\text {out }}=\frac{Q}{A} \text {. }
$$

For a barrel slope higher than the critical slope in the unsubmerged inlet condition (type 1 flow) or the submerged inlet condition (type 5 flow), supercritical flow occurs in the culvert barrel. In these two cases, the cross-sectional area of flow depends on the water depth in the channel barrel, which is assumed as the normal depth calculated from the Manning formula for a circular cross-section: 


$$
Q=\frac{1}{n} \cdot \frac{D^{2}}{8}(\beta-\sin \beta) \cdot\left(\frac{D}{4 B}(\beta-\sin \beta)\right)^{2 / 3} \cdot i_{0}^{1 / 2},
$$

where the centre angle $\beta$ corresponding to the normal depth is calculated from the rearranged form of equation (1):

$$
\beta=2 \cdot a \cos \left(1-\frac{2 h_{N}}{D}\right) .
$$

The solution of non-linear equation (11) in the real domain $\left(0 \leq h_{N} \leq D\right)$ was obtained by the bisection method (Szymkiewicz 2010).

For the unsubmerged inlet condition and subcritical flow in the barrel, the critical depth occurs in the outlet. In equation (10), the cross-sectional area of flow is equal to the critical area of flow. For critical flow, the outlet flow velocity was calculated by equation (3).

Figure 6 shows the results of the calculations of the headwall culvert outlet flow velocity for a variable headwater. A generally adopted values of the culvert slope (from 0.5 to 3.5 percent) were used in these calculations. In most cases, with the assumed Manning roughness coefficient $n=0.013 \mathrm{~m}^{-1 / 3} \mathrm{~s}$, supercritical flow is a dominant form of water flow through the culvert barrel. For the lowest slope in the analyzed range, supercritical flow occurs only in the unsubmerged inlet condition. As soon as the inlet becomes submerged, the normal depth is calculated with a higher value than the critical depth value, and subcritical flow occurs in the culvert barrel. A slight headwater increase changes the flow regime to pressure flow (type 6 flow).

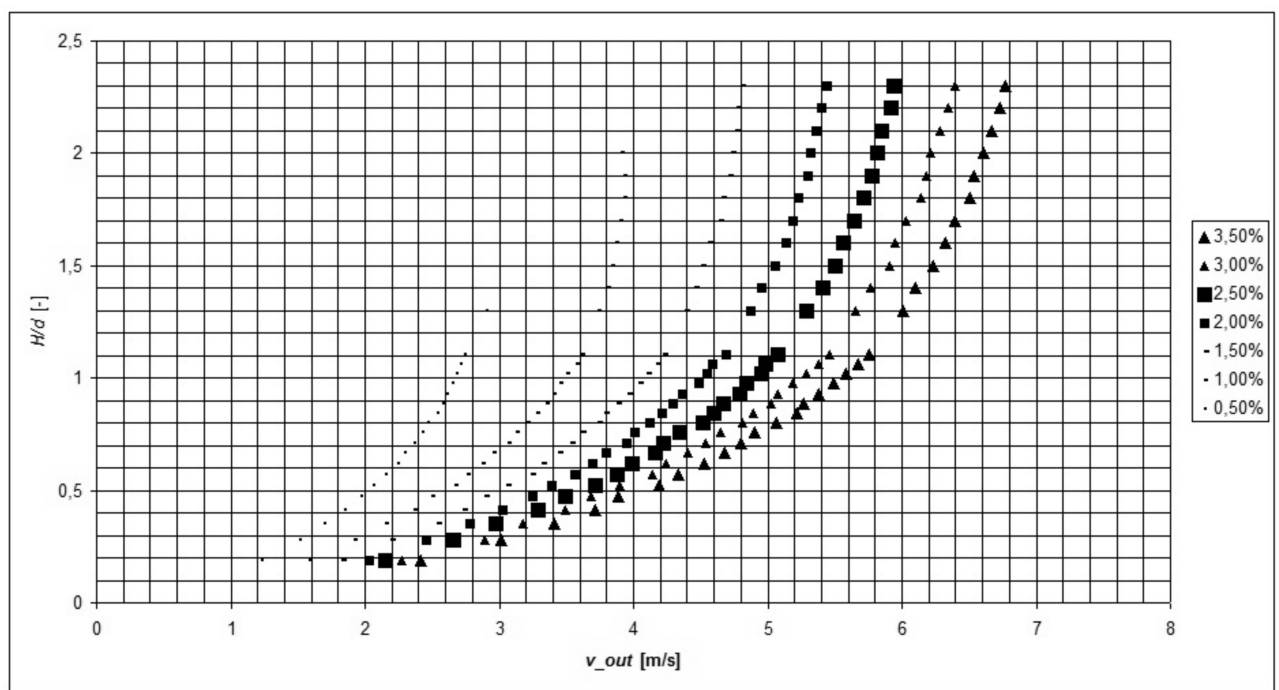

Fig. 6. Outlet flow velocity for the barrel height $D=1.2$ meter, variable barrel slope, and unsubmerged outlet conditions 
For higher values of the culvert slope, the outlet velocity increases. Assuming that the headwater height is twice the height of the barrel and with a culvert slope of $3.5 \%$, the outlet velocity can exceed 6.5 meter per second under unsubmerged outlet conditions when there is no tailwater impact on barrel flow. Such a high velocity is undesirable because of downstream scour, which can be dangerous for the culvert and the road structure.

\section{Conclusions}

In culvert design, one should avoid sudden rises in the headwater resulting from unpredictable changes between inlet, outlet and barrel flow control. The first step is to estimate the culvert discharge value, which requires the knowledge of hydrological processes. Natural conditions, such as the channel slope, limit culvert design possibilities. Depending on hydraulic parameters such as headwater, tailwater, critical depth and normal depth, the appropriate type of flow has to be selected for calculations to match actual conditions. One of the results of culvert design is the estimated outlet velocity. Because of the possible erosion of streambed or bank material due to flowing water, the outlet velocity should be limited to safe values of $0.45 \mathrm{~m} / \mathrm{s}$ for clay, $1.0 \mathrm{~m} / \mathrm{s}$ for gravel and about $2.0 \mathrm{~m} / \mathrm{s}$ for concrete and schist (Sawicki 2009). Polish regulations on culvert design published by the Minister of Transport and Maritime Affairs in 2000 (Journal of Laws of 2000, No. 63, item 735) suggest an allowable speed in the culvert of 3 or $3.5 \mathrm{~m} / \mathrm{s}$ (depending on the height of the culvert barrel). Unfortunately, under natural conditions in river valleys, hills and mountainous areas, the natural channel slope can be significant, which may result in huge outlet velocities and consequently in bottom scour processes downstream. In such cases, it is necessary to dissipate much of the energy by dissipators, such as stilling basins or vertical wells, which can dissipate energy without damage.

Depending on the hydraulic type of culvert water flow, the outlet velocity was calculated on the basis of the normal depth or the critical depth. However, owing to the assumed lack of impact of downstream on the culvert outlet, the real outlet velocity may reach higher values. This fact is included in Polish regulations (Journal of Laws of 2000, No. 63, item 735) as a correction parameter to calculated outlet depths.

The above-mentioned regulation on the technical conditions to be met by road engineering structures and their location states that, comparing with FHWA, only four types of culvert flow are included in a hydraulic calculations (types 2, 4-6). A comparison of the two documents shows that the regulations published by the Minister of Transport and Maritime Affairs recommend higher dimensions of the culvert cross-section with respect to the same data (Szpakowski 2013). For the unsubmerged inlet condition of flow, where supercritical flow occurs in the culvert barrel or there is a tailwater impact on barrel flow, the Polish law does not provide a clear recommendation for culvert design. 


\section{References}

Bodhaine G. L. (1968) (first printing) Measurement of Peak Discharge at Culverts by Indirect Methods. Techniques of Water Resources Investigation of the United States Geological Survey, U.S. Geological Survey, Washington.

Chanson H. (2004) The hydraulics of open channel flow: an introduction, Elsevier, Oxford.

Henderson F. M. (1966) Open Channel Flow, Macmillan publishing,New York, London.

French R. H. (2007) Open Channel Hydraulics, Water Resources Publications, LLC.

Regulation published by the Minister of Transport and Maritime Affairs on technical conditions to be met by traffic engineering structures and their location (Journal of Laws of 2000, No. 63, item 735) (in Polish).

Sawicki J. (2009) Flow mechanics, Wydawnictwo PG, Gdańsk (in Polish).

Schall J. D., Thompson P. L., Zerges S. M., Kilgore R. T., Morris J. L. (2012) Hydraulic design of highway culverts, U.S. Department of Transportation, Federal Highway Administration FHWA-HIF-12-026.

Szpakowski W. (2013) Estimation of the actual capacity of a road culvert, Drogownictwo, LXVIII (6), 189-192 (in Polish).

Szymkiewicz R. (2010) Numerical Modeling in Open Channel Hydraulics, Springer, Dordrecht, Heidelberg, London, New York. 